\title{
Digital manuscript submission
}

One of the key aspects of research is publication of that research. To this end the system of peer-reviewed journals has been serving the research and scientific community since 1651 and to date no-one has devised a more effective system. But, while the integrity of publications continues to benefit the scientific community through such a system, the individual authors and referees who work within the system tend to find it a laborious and lengthy paper exercise. That is why I am delighted to announce the launch of a new electronic manuscript submission system for the $B D J$ which was initiated on July 1st this year.

In my view the main benefits of this new system will be a speeding up of the whole process, especially for authors of papers. I greatly welcome this because of the often embarrassing delay between submission of a paper and final acceptance, caused by the complex process itself and sometimes by overworked referees who, these days, find refereeing a paper yet another burden in their already packed schedule. Although the $B D J$ is proud of its achievements in reducing acceptance to publication times from over 12 months (several years ago) to only 3-4 months today, we still need to address the delay from receipt of a paper to acceptance. I am confident this new system will achieve this, if only because it removes the inevitable delay in posting material.

Before examining the electronic system in more detail it is worth reminding ourselves of the $B D J$ s current paper manuscript submission system, which is much the same as all peer review processes in scientific publishing. On receiving a paper I will send it to two referees. When the reports from both referees are returned I will then send the manuscript plus reports to the scientific or clinical editor (depending on whether the paper is a research or practice paper) or the education advisor. They will return the manuscript with their advice and comments, and I then write to the author with a decision (accept, accept with modifications or reject). In most cases additional work is required for those we accept, so the author has to carry out the modifications and send the manuscript back, and usually the manuscript is finally accepted. In some cases manuscripts need to be seen by the statistical advisor and in certain cases I send modified manuscripts back to the scientific editor with queries where I am unsure and need advice. The process is indeed complex, and a large amount of time is spent in transit in the postal system (even worse for international papers). The new electronic system follows the same basic pattern, because it is essential we continue to protect the $B D J$ s reputation of scientific rigor and integrity. What has changed is the method of transmission. The system is web-based, so that all manuscripts are held in electronic form on the internet. I know this explanation is not strictly true, the files obviously live on a server somewhere, but I shall continue with the virtual analogy because I suspect it makes it easier to understand the process conceptually.

Thus authors submit their manuscripts (careful and detailed help on how to do this is provided on the site) which are converted to PDF files. These are then available to be read or downloaded and printed off. As soon as the manuscript is sent to the $B D J$ I receive a message informing me the manuscript has 'arrived'. I will select the referees in the usual way and they are informed by e-mail and can then access the paper on the web site. No-one else has access to the paper other than the author, the $B D J$ editorial staff and the referees. Authors can then track the progress of their manuscripts on the web site without having to contact the $B D J$ office, a real benefit for them.

The process then continues in the same fashion as for a paper manuscript except it all happens electronically. Naturally this is easier and faster than the old system, even though I suspect referees will print out manuscripts to read them. Despite everything we still have not found a substitute for the convenience of paper yet.

The electronic submission system went 'live' on July 1st with a pilot running for a couple of months while we sort out any unforeseen problems. I am confident there will be problems, but also confident we will overcome them. We will obviously continue to operate our paperbased system for those authors who prefer paper or who do not have access to the internet, but I look forward to the day when all our manuscripts are processed digitally.

Mike Grace m.grace.bdj@bda-dentistry.org.uk 